\title{
Operation and achievements of permanent referee system in Korea for establishment of fairness in Korean sports referee culture
}

\author{
Mi-suk Kim , Senior Researcher, Korea Institute of Sport Science, Hwarangro 727 Nowongu Seoul Korea, \\ 139804, \\ *Jeon, Sang-wan Jeon, Researcher, Kyonggi University, Gwanggyosanro Yeongtonggu Suwonsi Gyeonggido \\ Korea 16227, jsw3972@kspo.or.kr \\ ${ }^{*}$ Corresponding Author
}

\begin{abstract}
In 2014, a case occurred in which the parents of the player committed suicide due to biased judging by the referee in the selection of a representative taekwondo athlete in Seoul. With this opportunity, the KOC implemented a permanent referee system to establish a fair judging culture. Therefore, the purpose of this study is to examine the problems of the KOC's permanent referee system and draw up policy measures to improve them. This study was based on prior studies related to the subject matter and data such as documents and reports of standing judges of the KOC. This permanent referee system gives us the following policy implications. First, judging activities, educational activities, and research activities of permanent referees are managed reliably, and have a positive effect on fair judgment culture. Second, athletes, parents, leaders, association officials and general judges are highly satisfied with the operation of the permanent referee system. However, some permanent referees in the sport have raised questions about the evaluation method that does not take into account the specificity. Thus, in order for the permanent referee system to be expanded and operated in a more advanced manner, an agreement must be reached to improve the evaluation method and operation of the permanent referee system.
\end{abstract}

Keywords: Permanent referee, Fairness, Sports culture, Referee system, Operation, Achievement Received: 04.12.2020 Accepted: 10.01.2021 Published: 05.02.2021

\section{INTRODUCTION}

In a survey conducted by What's Next in March 2017 of Koreans with ages from 19 to 70 on "fairness in Korean society", 8 out of 10 (80.1\%) responded, "It is not fair". In particular, youths aged from 19 to 29 accounted for the largest among all respondents who think our society was not fair, at $83.8 \%$. The youths who will be the leaders of our society in the future were found to have the most pessimistic view of our society.

As often said, "Misjudgement is part of the game". It has been some kind of a custom in sports that athletes, related personnel and spectators accept the result of the game even with a misjudgement of a referee [1-3]. However, given that the misjudgement of a referee in sports does not just translate into a loss in a game to but also significant economic repercussions to athletes, some even argue that referees' judgement should not be controversial and cancellations should definitely be allowed for wrong judgements [4-6]. Nevertheless, according to Sport White Paper, the number of cases of reports on sports fairness was 200 , of which only 141 cases (70.5\%) were settled, with the rest still remaining controversial [7].

In particular, it is worth noting the case of a suicide of the father of an athlete who argued that there was a misjudgement in the game held to select athletes for Taekwondo team for Korea National Sports Festival in May 2013 came as a shock to the nation [8]. Upon police investigation, it was found that there was match fixing between the management of the Seoul Taekwondo Association and the referee. From this case and the ensuing investigation into the current status of operation of different sports associations, the government learned that most referee commissions are not playing the proper roles. In particular, it learned that most are having difficulty recruiting referees that temporary referees are filling in the place on the day of the game, and their pay was very low as well. This is a part of the problem caused by the low level of education and evaluation in the physical education field [9]. Most of all, associations were not applying the rules of the referee committees on the ground. In addition, our public has low trust in referees [10] that granting fairness in referees' judgement remains highly intractable. 
As such, the Ministry of Culture, Sports and Tourism (MCST) newly introduced the Permanent Referee System, or PRS, led by the Korean Olympic Committee (KOC) in May 2014. It is the only system giving the sole authority of referee operation to the KOC, which was a wake-up call to the Korean sports circles and its fairness. The KOC selects and manages referees for 11 games (Taekwondo, basketball, Judo, baseball, handball, figure skating, short track speed skating, ice hockey, wresting, hockey, and rugby), an unprecedented system in any other countries.

Thus, this study aims to look into the Korean society and the sports circles through the 5-year-old PRS, and tack stock of its achievements. In addition, it seeks to review whether the system is worth maintaining as a solution to recover fairness in our sports circles. While currently there is some on-going research looking into legal systems and domestic research on fairness of sports judgement as of late $[8,10$, $11,12,13]$, fairness and ethicality of the introduction of a reader $[14,15]$, or perception study on referee judgement $[16,17]$. This study, however, is differentiated from the existing research in that it analyzes various significant issues that need to be discussed with the introduction of the system by looking into the very essence of sports, while revealing the achievements of the new PRS. On this basis, this study will provide important implications for informing the public of the need to apply the system for fairness and expanded application of the system in future policies. It will also show the importance of the meaning of education in the sports field [18].

\section{Materials and methods}

\section{2-1. Subjects of research}

The permanent referees, general referees, relevant officials from associations, athletes, coaches and athletes' parents were designated as the subjects of this research in order to analyze the PRS for the recovery of fairness in Korean sports circles. The games and scale of the subjects are indicated in the following table:

Table 1. Research subjects for the recent 4 years

\begin{tabular}{l|l|l}
\hline & \# of permanent referees & $\begin{array}{l}\text { \# of general referees, officials from associations, } \\
\text { athletes, coaches, and parents }\end{array}$ \\
\hline \hline 2015 & 76 people for 10 games & 517 people \\
\hline 2016 & 73 people for 10 games & 541 people \\
\hline 2017 & 73 people for 10 games & 1441 people \\
\hline 2018 & 100 people for 19 games & 2110 people \\
\hline
\end{tabular}

\section{2-2. Method of analysis}

This study utilized the sourcebook on ${ }^{\circledR}$ Evaluation of PRS Operation』issued four times from 2015 to 2018 by the MCST. The compensation methods of moving average were used to show the trends. In addition, the data was arranged by securing the same items, integrating similar items, and subjugating short-term items.

\section{2-3. Contents of research}

As for permanent referees, the content of research was selected around the results of referee evaluation analysis (from 2015 to 2018). For athletes, coaches, athletes' parents, the result of the satisfaction survey on the PRS operation (from 2015 to 2018) served as the reference. In specific, (1) date of referee and assignment activity, (2) date of rotation-based coaching and training, and (3) date of referee research activity were chosen for the content of research for permanent referees, while (1) clarity of formal objections, (2) improvement in game operating capacity, (3) accuracy of referee judgement, and (4) settlement of misjudgement and handling were selected as the content of research for athletes, coaches, athletes' parents, and relevant officials of associations.

\section{2-4. Method of Data Treatment}

In this study, the statistics analysis program IBM SPSS Statistics 21.0 was used for data analysis in order to statistically encode all data collected. The average value of each response and standard deviation were analyzed through technical statistics, and frequency analysis was conducted as well.

\section{What is the PRS?}


The PRS is intended to "expand a fair judgement culture and create a transparent environment in sports by guaranteeing referee independence and improving qualification and expertise through the enhanced condition in referee activities", as presented by the Korean Olympic Committee (KOC) [19]. Permanent referees are independent of the referee committees of each association, paid a fixed amount every month (KRW 3 million before tax), and are mainly tasked with referee assignment, training, and research. According to the PRS guidelines by the KOC, referee assignment is for referees to serve in nationwide events recognized by the KOC or international events. The training part of their job description refers to participating in training sessions organized by the KOC or associations, or providing lectures for training approved by the associations. The research part refers to the activities for self-development as a referee.

Table 2. Relevant agencies operating PRS

\begin{tabular}{|c|c|c|c|c|}
\hline & MCST & KSOC & $\begin{array}{ll}\text { PRS } & \text { operating } \\
\text { associations } & \\
\end{array}$ & $\begin{array}{l}\text { Korea Institute of Sports } \\
\text { Science (KISS) }\end{array}$ \\
\hline Period & $\begin{array}{l}\text { Around } \\
\text { every } \\
\text { January }\end{array}$ & $\begin{array}{l}\text { Around every February } \\
\text { (Immediately after the } \\
\text { approval by the MCST) }\end{array}$ & $\begin{array}{l}\text { Around every February } \\
\text { (Immediately after the } \\
\text { approval by MCST and } \\
\text { KSOC) }\end{array}$ & $\begin{array}{l}\text { Around every November } \\
\text { and December }\end{array}$ \\
\hline Role & $\begin{array}{l}\text { Set up plans } \\
\text { for PRS }\end{array}$ & $\begin{array}{l}\text {-Operate and manage } \\
\text { PRS } \\
\text {-Select games for PRS } \\
\text {-Select final permanent } \\
\text { referees } \\
\text {-Manage monthly PRS } \\
\text { reports } \\
\text {-Train permanent } \\
\text { referees } \\
\text { - Handle tax settlement } \\
\text { for PRS project }\end{array}$ & $\begin{array}{l}\text {-Request the KSOC for } \\
\text { support for PRS } \\
\text {-Recruit permanent } \\
\text { referees (as } 3 \text { times as } \\
\text { needed) } \\
\text {-Assign referees on the } \\
\text { ground and support } \\
\text { activities }\end{array}$ & $\begin{array}{l}\text {-Conduct awareness and } \\
\text { satisfaction surveys } \\
\text {-Personal evaluation of } \\
\text { permanent referees } \\
\text { ※ Result to serve as a } \\
\text { basis for re-signing of PRS } \\
\text { contracts }\end{array}$ \\
\hline
\end{tabular}

As mentioned above, the PRS is unprecedented globally. It is because managing and operating 'referees' is tricky considering the different characteristics and roles of referees by game. Still, the government and the KOC created this new referee system independent of the associations as they experienced the repercussions of a misjudgement of a referee undermining the value of sports. The MCST, the KOC that manages the PRS, the associations for the particular game that assigns and supports the permanent referees, and Korea Institute of Sports Science (KISS) are in fact working closely with one another. $<$ Table $2>$ below shows the relationship of the relevant agencies and their roles.

The number of permanent referees was 70 for 9 games back in 2014, which grew by 52\% to 125 for 19 games, with the number of games with the PRS increasing by $42 \%$ (Refer <Table $3>$ ).

Table 3. Status of operation of permanent referees by year

\begin{tabular}{l|l|l|l|l|l|l}
\hline Category & $\mathbf{2 0 1 4}$ & $\mathbf{2 0 1 5}$ & $\mathbf{2 0 1 6}$ & $\mathbf{2 0 1 7}$ & $\mathbf{2 0 1 8}$ & $\mathbf{2 0 1 9}$ \\
\hline \hline \# of games & 9 & 10 & 10 & 10 & 19 & 19 \\
\hline \# of referees & 70 & 76 & 73 & 73 & 100 & 125 \\
\hline Period of operation (months) & 7 & 11 & 11 & 11 & 11 & 11 \\
\hline
\end{tabular}

Meanwhile, the amount of pay for referees from 40 associations was on average KRW 80,000 per day [10]. This amount excludes room and board, but most associations include the expense on transportation and gas in the above-mentioned amount of pay, leading many to consider the referee activities as part of volunteer works. The very low pay is considered as the cause of corruption among some referees, which was the reason the PRS was created where referees are paid a fixed amount. The overview of the amount of pay is indicated in $<$ Table $4>$ below.

Table 4. Amount of pay for permanent referees (2019)

\begin{tabular}{l|l|l}
\hline days of work (Month) & Payment of allowance (KRW) & Notes \\
\hline \hline
\end{tabular}




\begin{tabular}{|c|c|c|}
\hline $\begin{array}{l}\text { Over } 15 \text { days } \\
12 \sim 14 \text { days }\end{array}$ & $\begin{array}{l}\text { (a) } 3,000,000 / \text { (b) } 2,500,000 \\
\text { (a) } 2,500,000 / \text { (b) } 2,000,000\end{array}$ & \multirow{3}{*}{$\begin{array}{l}\text { (a) If requirements on } \\
\text { assignment were met } \\
\text { (b) If requirements on } \\
\text { assignment were not met }\end{array}$} \\
\hline 7 11 days & (a) $2,000,000 /$ (b) $1,500,000$ & \\
\hline $1 \sim 6$ days & $\begin{array}{l}\text { (a) } 3,000,000 / \text { (\# of days of the month) } \\
\times(\# \text { of days worked) } \\
\text { (b) } 2,500,000 / \text { (\# of days of the month) } \\
\times \text { (\# of days worked) }\end{array}$ & \\
\hline
\end{tabular}

The above <Table 4> shows the difference in the amount of pay by month, which is based on the PRS guidelines of the KSOC. As mentioned above, permanent referees can be paid once they fulfilled three major duties, which include referee activities, training and research activities. The number of days on which the three activities are done should be 15 days, of which there should be at least over 10 days (mandatory) of referee assignment, a minimum of 3 and a maximum of 4 days of research and a minimum of 1 day and a maximum of 2 days of training.

The KSOC sets the number of days of activities (15 days in total) to manage the permanent referees and the KISS evaluates referees based on the activity report submitted by the permanent referees and analyzes the satisfaction on the PRS by conducting surveys of the stakeholders in games with the PRS including athletes, coaches, officials from associations and general referees every year.

\section{Results}

Operated since 2014 (pilot year) to 2019, the overall achievements from the PRS can be largely twofold. First, the quantity and the quality of the permanent referee activities have improved. Second, the satisfaction in referee operation has increased. The performance of permanent referees can be checked by looking at the number of days spent on (1) referee (assignment) activities, (2) training, and (3) research per year, details of which are as follows:

\subsection{Referee activities}

$<$ Table $5>$ and $<$ Figure $1>$ show the result of referee activities by the permanent referees for the past 4 years. The year 2015 was when the PRS was officially introduced, when the most number of referees were assigned to ice hockey. Meanwhile, upon looking at the average number of days of referee activities by year from 2015 to 2018, 2016 saw the most number of referees in all games. This is because it was in the beginning stage of the PRS implementation. Three and four years into the operation, the number of days with permanent referees gradually decreased. For example, with ice hockey, it was 199 times a year or 17 days in a month on average in 2016 (11 months), which declined to 143 days a year or 13 days a month on average in 2018. It can be expected that the gradual decline has taken place as the PRS operation has stabilized to some degree.

Table 5. Trend of referee assignment in recent four years (Annual average)

\begin{tabular}{l|l|l|l|l|l}
\hline & Sports & $\mathbf{2 0 1 5}$ & $\mathbf{2 0 1 6}$ & $\mathbf{2 0 1 7}$ & $\mathbf{2 0 1 8}$ \\
\hline \hline 1 & Basketball & 114.5 & 183 & 131 & 130.2 \\
\hline 2 & Rugby & 74.4 & 123.5 & 86.75 & 93.57 \\
\hline 3 & Wrestling & 96.3 & 179.6 & 117.63 & 118.75 \\
\hline 4 & Baseball & 95.8 & 142.9 & 122.9 & 131.9 \\
\hline 5 & Ice skating & 42.8 & 89.3 & 58.67 & 77.16 \\
\hline 6 & Ice hockey & 170.2 & 188.7 & 168.17 & 143.83 \\
\hline 7 & Judo & 81.1 & 161.5 & 116.5 & 119 \\
\hline 8 & Taekwondo & 101.3 & 188.1 & 115.7 & 127.2 \\
\hline 9 & Hockey & 112 & 130.5 & 135 & 113.5 \\
\hline 10 & Handball & 115.7 & 148.3 & 88.56 & 107 \\
\hline & & & & &
\end{tabular}




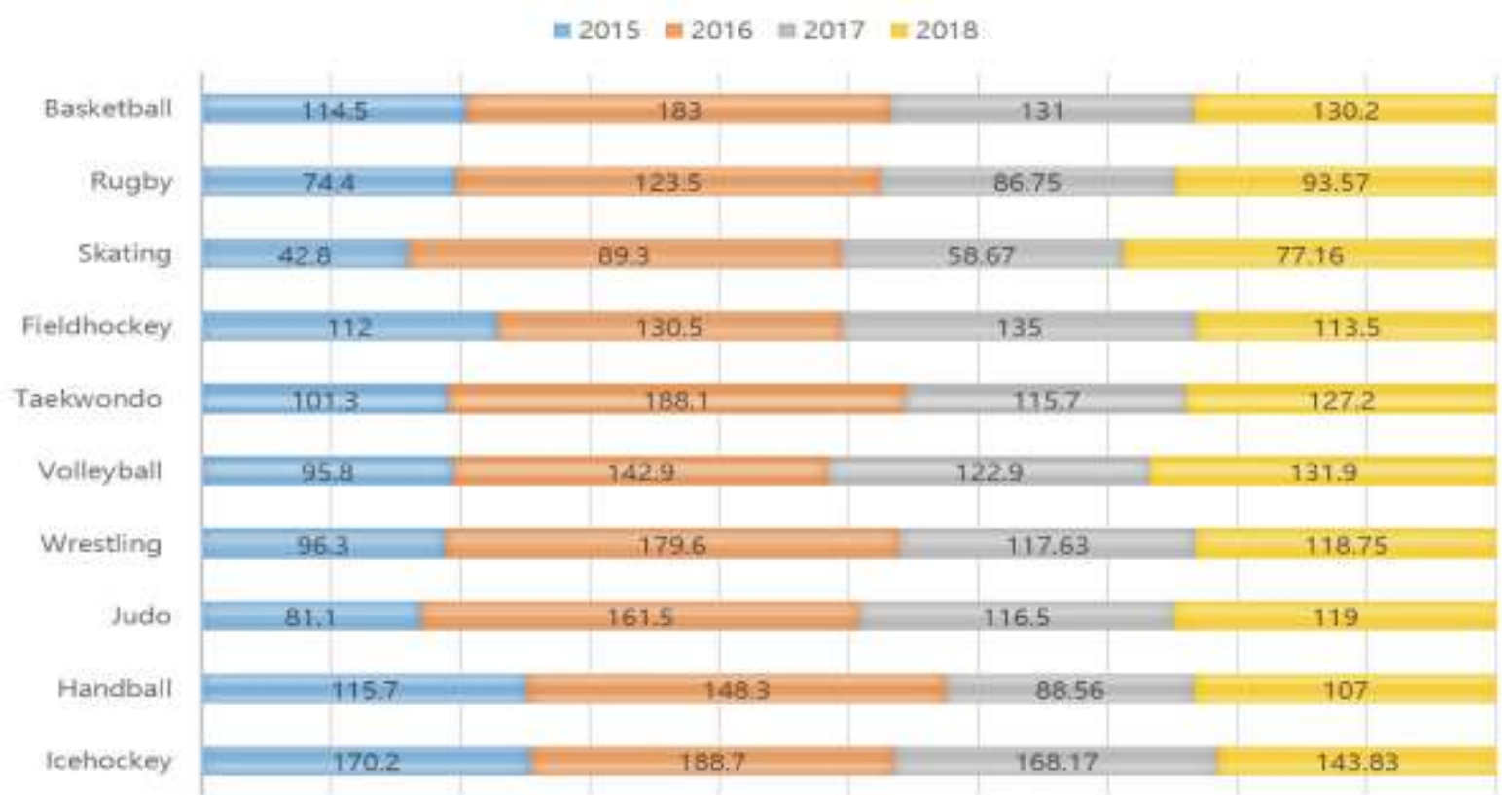

Figure 1. Trend of referee activities by permanent referees by game in recent four years

\subsection{Training}

$<$ Table $6>$ and <Figure 2> are the overview of the past four years of training activities by permanent referees. Training duties refer to permanent referees participating in the training activities organized by the KSOC and related associations. Permanent referees can either be learners or lecturers. Training activities have different characteristics by game. In the case of ice hockey in 2016, the number of days with referee activities was 188, while the number of days with training activities was 3.7 days which was the lowest among all duties. This means that with increased days of referee activities, training and research activities relatively decline.

Table 6. Trend of training activities in recent four years

\begin{tabular}{l|l|l|l|l|l}
\hline & Sports & $\mathbf{2 0 1 5}$ & $\mathbf{2 0 1 6}$ & $\mathbf{2 0 1 7}$ & $\mathbf{2 0 1 8}$ \\
\hline \hline 1 & Basketball & 29.0 & 41.75 & 35 & 19 \\
\hline 2 & Rugby & 28.3 & 9.5 & 44.37 & 35.42 \\
\hline 3 & Wrestling & 38.9 & 8.8 & 13.25 & 34.75 \\
\hline 4 & Baseball & 38.3 & 11.3 & 26.3 & 33.8 \\
\hline 5 & Ice skating & 32.5 & 18.2 & 39.67 & 26 \\
\hline 6 & Ice hockey & 21.3 & 3.7 & 13.5 & 18.5 \\
\hline 7 & Judo & 11.6 & 12.0 & 29.75 & 32.75 \\
\hline 8 & Taekwondo & 19.0 & 22.4 & 37.1 & 33.3 \\
\hline 9 & Hockey & 13.9 & 57 & 23 & 18 \\
\hline 10 & Handball & 22.7 & 10.3 & 17.56 & 22.75 \\
\hline
\end{tabular}




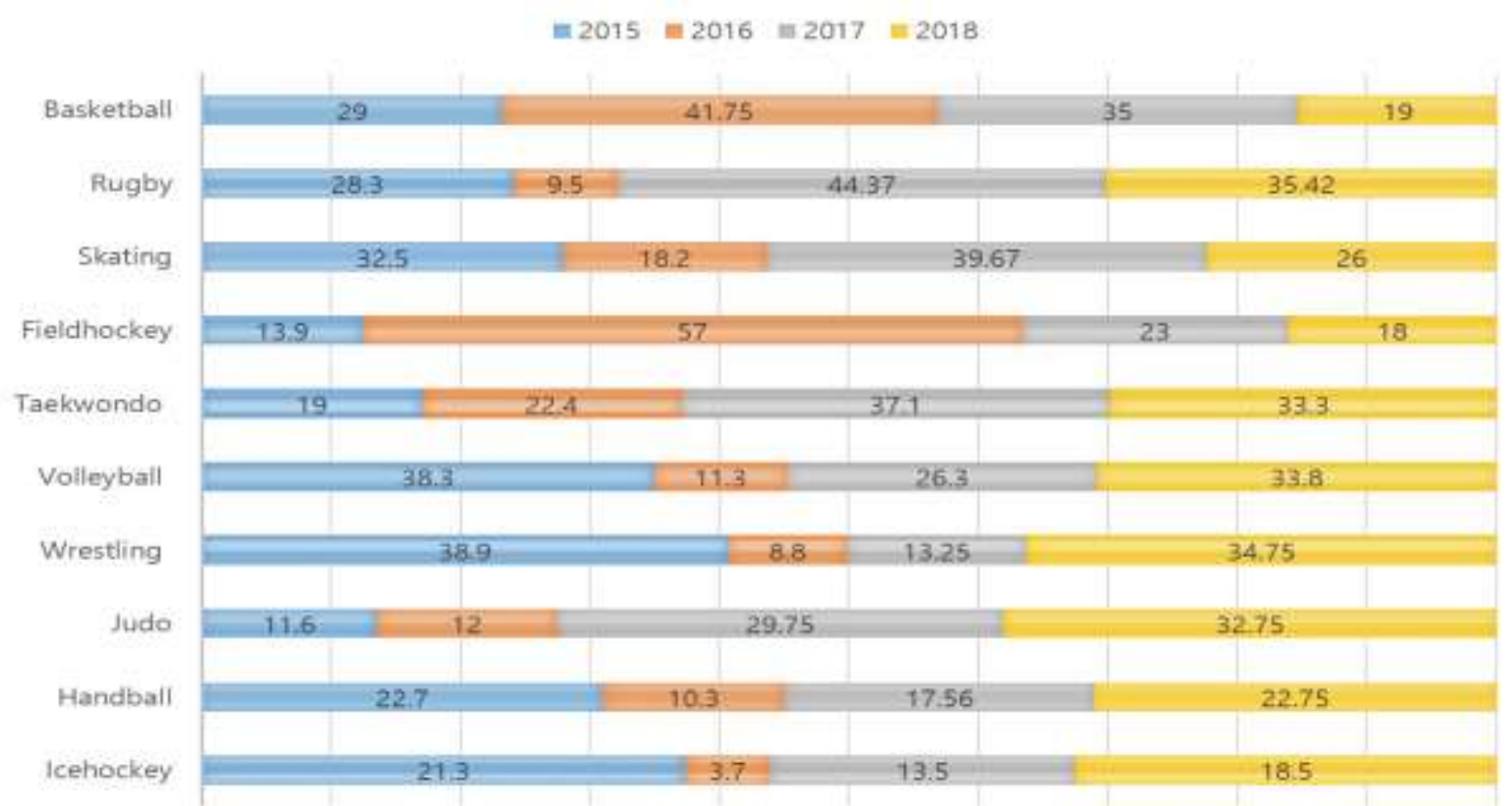

Figure 2. Trend of training activities in recent four years by game

\subsection{Research activities}

$<$ Table $7>$ and $<$ Figure $3>$ show the trend of research activities by permanent referees in recent four years. Research activities are intended to strengthen individual referee expertise, which includes research in game rules or acquisition of license. In the early stage of the project, there was a low understanding of research activities for most games. However, as time went by, the overall number of days spent on activities increased gradually. In particular, ice skating sports saw a concentration on research activities as they are seasonal sports.

Table 7. Trends of research activities in recent four years

\begin{tabular}{l|l|l|l|l|l}
\hline & Sports & $\mathbf{2 0 1 5}$ & $\mathbf{2 0 1 6}$ & $\mathbf{2 0 1 7}$ & $\mathbf{2 0 1 8}$ \\
\hline \hline 1 & Basketball & 0.5 & 11 & 8.2 & 9.8 \\
\hline 2 & Rugby & 0.6 & 4.5 & 12.62 & 13.85 \\
\hline 3 & Wrestling & 0.0 & 8.2 & 0.0 & 11.25 \\
\hline 4 & Volleyball & 0.0 & 9.8 & 8.8 & 21.2 \\
\hline 5 & Ice skating & 0.0 & 53.8 & 51 & 87.33 \\
\hline 6 & Ice hockey & 0.0 & 20.7 & 7.67 & 17.66 \\
\hline 9 & Judo & 0.5 & 8.4 & 11.87 & 33.75 \\
\hline 10 & Taekwondo & 0.0 & 1.1 & 3.3 & 2.3 \\
\hline
\end{tabular}




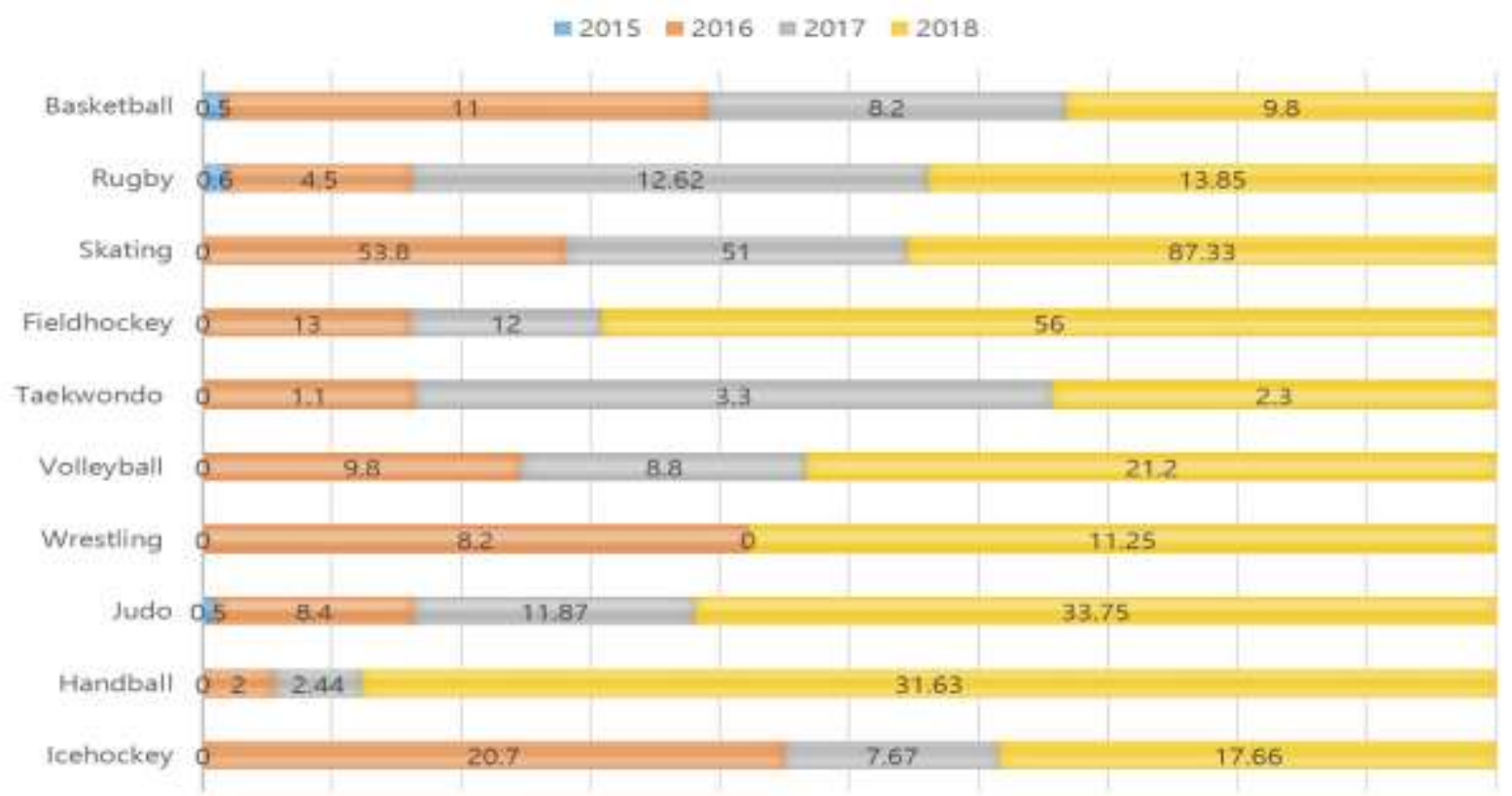

Figure 3. Trend of research activities of permanent referees by game in recent four years

Next, the satisfaction in referee operation has increased. The researchers conducted surveys of athletes, parents of athletes, coaches and related officials of associations every year. The items of survey were whether the PRS (1) contributed to the improved accuracy in the treatment of formal objections, (2) improved game operation capacity, (3) made judgement clearer, and (4) made misjudgement handling more prompt. The satisfaction in this regard is indicated in $<$ Figure $4>$ below.

Upon conducting satisfaction surveys of the PRS, it was found that satisfaction was mostly hovering above 3.5 points out of 5 except for the first year of implementation. However, the average score was low at 3.1 points only in 2016. This may have been caused by seasonal effect, as the Rio Olympics took place in 2016 and people may have reacted sensitively to the "referees' judgement". After 2016, the score went up slightly or remained stagnant, which calls for the need to identify some detailed factors causing issues with the PRS and respond accordingly to raise satisfaction level on the ground.

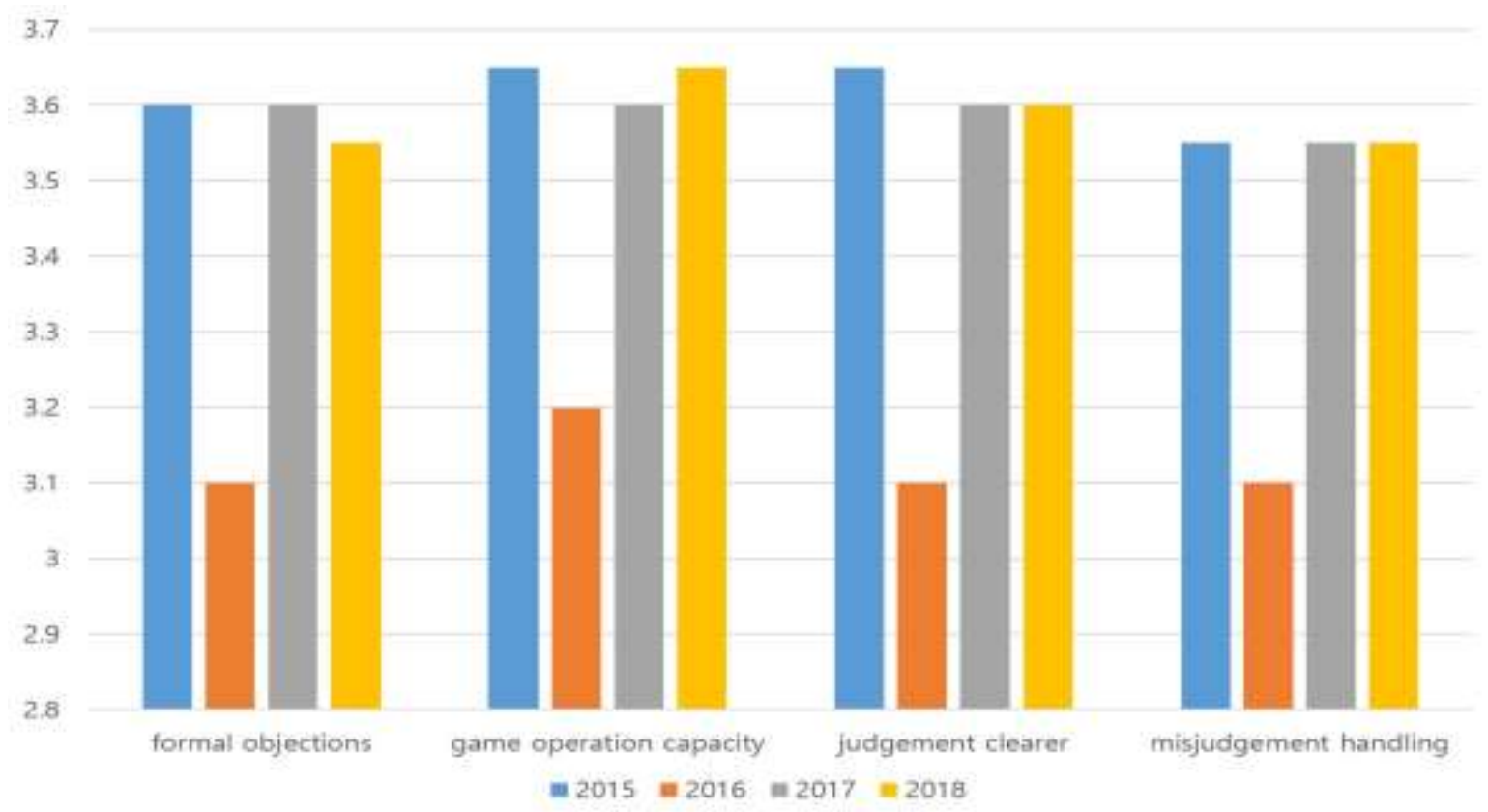

Figure 4. Satisfaction in the operation of the PRS 


\section{Conclusion}

This study seeks to analyze the achievement of the PRS which was introduced to recover fairness in Korean sports culture and identify areas of improvement to enable expanded operation.

The PRS is an unprecedented system in any other country, as it is primarily managed not by the associations but by the KSOC which managing the associations as a whole. The KSOC operates 125 permanent referees for 19 games since 2014, and each referee is engaging in activities for games ranging from judgement, training, and research, which are subject to annual evaluations.

According to the guidelines for the PRS by the KSOC, it is important to "secure independence and expertise of referees by improving the working conditions, thereby creating a fair and transparent sports environment through strengthened qualification and capacity".

As such, permanent referees are duty-bond to perform referee activities and engage in training and research activities to strengthen expertise and capacity with a monthly pay of KRW 3 million. The results above show the details of the referee, training, and research activities that they performed in a given year, though they may slightly differ by game. Three years into the introduction of the system, the KSOC seems to be operating the system rather stably albeit slight differences by game. For example, as for ice hockey, referee activities used to take up the lion's share of all activities in the beginning stage. However, after three years, they were balanced out with increased training and research activities, which means that the intended purpose of the system has been understood.

Meanwhile, the satisfaction level of athletes, parents, coaches, relevant officials from associations, and general referees has seen an increase from the beginning year, but has decreased in 2016. This may have been caused by seasonal effect, as the Rio Olympics took place in 2016 and people may have reacted sensitively to the result of the games as well as referees' decisions. However, even after 2017, satisfaction level of the PRS has stagnated. To this end, the associations and the KSOC have to identify the reason and respond to it together.

Despite high satisfaction in the system, it is not without controversies. There exist some issues from operating 125 permanent referees for 19 different games under the PRS. First is whether it is possible to evaluate the referees under the same framework of evaluation. Second is whether the quantitative evaluation (number of days worked) is objective enough. The games that will be immediately affected by these questions will be ice skating (figure skating, short track speed skating), field hockey, and Wu Shu, for which sports events are held for less than 10 days in a month, which is significantly lesser than other games. Also, it can be argued that when the qualitative evaluation from referee commissioner of the associations is added, can we guarantee the objectivity and the reliability of the evaluation. Once such evaluations are added, the intended purpose of the system "independence of referees" will not be delivered. Thus, it may be considered but it requires prudence.

Starting with 70 referees for 9 games in 2014, there currently are 125 referees for 19 games on the ground. The increasing number of games and referees is proof that the system is settling stably, and is contributing to fairness of the events. There is a growing expectation that going beyond simply enhancing fairness on the ground, the system should be able to raise awareness of the importance of fairness in our society, thereby creating a healthier society down the road. Based on the result and the conclusion of this study, the researchers would like to make a few recommendations as follows.

There is a significant lack of advanced research and relevant data on the PRS which was created to contribute to the expansion of a fair and a transparent sports culture by fostering amateur sports referees. In particular, while it is possible to propose directions and identify areas of improvement, it is not feasible to do a comparison study as the system exists only in Korea. Given that, various research methods should be applied to future research so that a profound analysis of the characteristics of the PRS can be made feasible.

\section{Acknowledgements}

This study was conducted "Evaluation of the Operation of the Permanent Referee System" with the support of Korea Institute of Sport Science in 2018.

\section{References}

[1] Ciomaga, B. Conventionalism Revisited. Sport, Ethics, and Philosophy. 2012;6(4):410-422.

[2] Morgan. W. The normativity of sport: a historicist take on broad internalism. Journal of the Philosophy of Sport. 2015;43(1):27-39.

[3] Simon, R. Internalism and internal values in sport. Journal of the Philosophy of Sport. 2020;27(1):1-16.

[4] Kim D. G. A study on rigorous introduction of electronic refereeing system \& video - based decision 
system for fairness of sports. Journal of Sports and Entertainment Law. 2016;19(3): 45-62.

[5] Kretchmar, S. Pluralistic internalism. Journal of the Philosophy of Sport. 2015;42(1):83-100.

[6] Russell, J. Coaching and undeserved competitive success. In R. Simon (Ed.), The Ethics of Coaching Sports: Moral, Social and Legal Issues. Boulder, CO: Westview Press, 2013. p. 103-119.

[7] Ministry of Culture, Sports and Tourism. 2017 Sport White Paper [Internet]. 2017 [cited 2020 Jul 5]. Available from: https://www.sports.re.kr/front/board/bs/boardView.do?board_seq=47\&menu_seq=597\&con_seq= 3957

[8] Korea Institute of Sports Science. A study on the improvement of permanent referee system of the KOC. Research reports [Internet]. 2017 [cited 2020 Jul 15]. Available from: /front/research/project/orginView.do?menu_seq=594\&pageno=1\&artctrlno=RR_612780\&bibctrlno $=$ RR_612780\&lib_seq=

[9] Jing Li. \& Kim S. Y. On the development direction and policy of Chinese school physical education under the background of 'Healthy China 2030 Program'. International Journal of Emerging Multidisciplinary Research. 2019;3(1):21-27.

[10] Korea Institute of Sports Science. Current status and improvement of referees' management for members of the KOC. Research reports [Internet]. 2016 [cited 2020 Jul 8]. Available from: /front/research/project/orginView.do?menu_seq=594\&pageno=1\&artctrlno=RR_302733\&bibctrlno =RR_302733\&lib_seq=

[11] Nam K. Y. \& Kim D. H. Legal and institutional establishment for eradicating of scandals of leader and judge. Dankook Law Riview. 2016;40(4):65-98.

[12] Yeun K. Y. Legal issues of integrity in sports games -focusing on the legal responsibility for matchfixing. Journal of Sports and Entertainment Law 2015;18(4):173-204.

[13] Kim S. K. \& Moon J. T. A study for ensuring of fairness of sports under the constitution of Korea. Journal of Sports and Entertainment Law. 2014;17(2):71-99.

[14] Park S. J. Ethical issues on umpiring and decision-aid technology. Journal of the Korean Society for the Philosophy of Sport, Dance \& Martial Arts. 2018;26(2),:31-41.

[15] Seo K. H. Exploration on video decipher for fairness in basketball. Journal of the Korean Society for the Philosophy of Sport, Dance \& Martial Arts. 2011;19(2):37-52.

[16] Jung H. D. A study on referee judgment differences between international referees of taekwondo. Taekwondo Journal of Kukkiwon. 2011;2(2);:97-108.

[17] Park J. J. \& Park S. S. The understanding of referee's decision factor and improvement way in Kumdo competition. Journal of Korean Alliance of Martial Arts. 2012;14(3):149-161.

[18] Remedios Ocampo-Azarcon. Teacher' perceptions of classroom assessment skills and literacy: An inquiry to the teachers of teachers. International Journal of Emerging Multidisciplinary Research 2017;1(1):91-99.

[19] Ministry of Culture, Sports and Tourism. A study on the operation of the standing judgment system. Research reports [Internet]. 2019 [cited 2020 Mar 11]. Available from:/front/research/project/orginView.do?menu_seq=594\&pageno=1\&artctrlno=CR_302125\&bibc trlno=CR_302125\&lib_seq= 